\title{
Adult videogame consumption as individualised, episodic progress
}

Article

Accepted Version

Molesworth, M. and Watkins, R. D. (2016) Adult videogame consumption as individualised, episodic progress. Journal of Consumer Culture, 16 (2). pp. 510-530. ISSN 1741-2900 doi: https://doi.org/10.1177/1469540514528195 Available at https://centaur.reading.ac.uk/79216/

It is advisable to refer to the publisher's version if you intend to cite from the work. See Guidance on citing.

To link to this article DOI: http://dx.doi.org/10.1177/1469540514528195

Publisher: Sage

All outputs in CentAUR are protected by Intellectual Property Rights law, including copyright law. Copyright and IPR is retained by the creators or other copyright holders. Terms and conditions for use of this material are defined in the End User Agreement.

\section{www.reading.ac.uk/centaur}

\section{CentAUR}

Central Archive at the University of Reading

Reading's research outputs online 


\title{
Adult videogame consumption as individualised, episodic progress
}

Molesworth, M. and R.D. Watkins. Forthcoming. "Adult Videogame Consumption as Individualised Episodic Progress.” Journal of Consumer Culture. DOI: 10.1177/1469540514528195

\begin{abstract}
Drawing from phenomenological interviews with 24 adult videogamers, we explore videogame consumption as a source of individualised, episodic progress. We first consider the relationship between play, progress, technology and the market. We then document adults' accounts of progress through the acquisition of new consoles and software, in the accumulation of in-game resources, and in creative achievements within videogames. Alongside an understanding of technological improvements as representing both technological and personal progress, we see how individuals may also turn to videogames in search of quick and easy episodes of achievement; here, progress is not some grand plan, but a series of small events helpfully structured by the latest game releases. Thus, in a society which aspires to a life where things 'get better' and time is usefully spent, adults who fail to actualise progress elsewhere may use videogames and related hardware to perform the idea of achievement as individualised episodes of play. In integrating the accepted cultural idea of progress, perceptions of adult play as 'frivolous' can be overcome and such practices may be normalised as a legitimate adult activity. However, play emerges from its frivolousness as legitimate only in compensating for working practices that remain alienated through technology-driven productivity, and through the latest technological commodities. The enjoyable nature of games as a leisure pursuit can become overshadowed by an obligation to achieve at the same time as distancing players from areas of their lives where progress is not experienced.
\end{abstract}

\section{Keywords}

Progress, play, achievement, videogames, leisure, labour 
The script for advertising agency TBWA's award winning advertisement for the original PlayStation is presented by a total of 19 videogame players of various ages from young child to pregnant mother to old man:

"For years, I've lived a double life. In the day, I do my job, I ride the bus, roll up my sleeves with the hoi polloi. But at night, I live a life of exhilaration, of missed heartbeats and adrenalin. [...] You may not think it to look at me but I have commanded armies and conquered worlds. And though in achieving these things I've set morality aside, I have no regrets. For though I've led a double life, at least I can say I've lived."

The advertisement invites individuals, including adults, to compare their mundane and alienating everyday lives with their engagement with videogames, where they are able to truly experience some sense of 'really living'. In the last 30 years, videogaming has become a popular adult leisure activity as individuals continue playing into adulthood (Mintel, 2011). While adult videogaming is now commonplace, positioned by both advertising and academic literature (Denegri-Knott and Molesworth, 2010; Molesworth, 2009) as a realm for escapism and fantasy, Thornham (2009) has highlighted the uneasy relationship between videogame play and perceptions of 'normal' adult behaviour. Consequently, videogamers must account for this activity as a serious and logical pastime in public discourse (Thornham, 2009, 2011). In this article, we further consider the ways in which players, especially adult men, make sense of individualised videogame consumption that may be viewed as 'weird' or 'geeky' and therefore harder to admit to than the social gaming that Thornham has considered previously. Our focus is not on experiences of play itself, but on contextualising a wider, reflexive sense-making activity (Askegaard and Linnet, 2011; Holstein and Gubrium, 2005). We specifically consider the ways in which adults rationalise videogame consumption as a location for achievement, and drawing from Bauman's (2000) description of liquid modernity, we consider adult videogame consumption as individualised, 'episodic progress', rooted in a need for a life in which things 'get better' and time is usefully spent, coupled with a failure to fully actualise this elsewhere.

Our contribution is to an understanding of the ways in which individuals, and perhaps especially men, reproduce cultural ideals (the desirability of progress) in new ways through specific consumption practices (of videogames and related hardware), and in doing so overcome other discourses associated with those practices (videogames as frivolous or childish). We contextualise these findings within a broader shifting of the location of 'progress projects' from the societal level and the domain of paid work, to private, playful 'episodes' of consumption. We begin by considering why progress may have become a significant discursive practice in videogame use, before reviewing adult videogamers' accounts of play as a source of achievement and progress. We conclude by discussing the implications of a lifeworld where consumption as 'working on play' to achieve progress has become a way of experiencing the promises understood still to be made by modernism.

\section{Individualised, episodic progress}

The deepest, perhaps the sole meaning of progress is made up of two closely interrelated beliefs - that 'time is on our side' and that we are the ones who 'make things happen'

(Bauman, 2000: 132)

Bauman (2000) considers progress as a self-confidence in the ability to sustain a forward-moving trajectory towards a better life, the lack of which results in the "absence of an agency able to "move the 
world forward"' (p. 133). He notes that while trust in societal progress has waned as the promise of a future happy society painted in so many eras has repeatedly failed to be fulfilled, our belief that our lives must be worked on and improved remains. Thus, progress is no longer framed as a means to achieve utopia, but as an ongoing and necessary project that must be continuously worked on at an individual level (Bauman, 2000).

Explicit in the history of consumption (and labour) is the growth of such individualism, and Gabriel and Lang (1995) note that the central justification for the organising of society around capitalism is individual, rational 'choice' that drives efficiency in markets and encourages innovation. Bauman (2000) argues that this has resulted in a reduction in societal control in favour of individual rights and responsibilities, and that progress 'like so many other parameters of modern life, has now been “'individualised_; more to the point - deregulated and privatized' (p. 135). Whereas previous 'top heavy' modernism placed responsibility for progressive change on society as a whole, in more recent 'bottom heavy' modernism the individual is made responsible for bettering their own circumstances (Bauman, 2001). In neoliberal modes of governance, the subject must take charge of their own wellbeing, self-actualizing through their own labour (Walkerdine and Bansel, 2010) in order to pursue a biographical project of self-realisation (Rose, 1999). The myth of progress, and its movement from a societal level to individual progress projects, has produced a perpetual state of individual striving, leading to an 'episodic life' where events are seen for their own merits but are unconnected both to one another and to other people (Bauman, 2001). Under such conditions, individuals blame themselves, rather than societal forces, for their failure to progress and consequently may have difficulty choosing and committing to progress projects (Walkerdine and Bansel, 2010). Bauman's complaint is that individuals who strive for progress because they experience a lack purpose in life may come to desire instant gratification through individualised episodes of progress distinct from any wider and more meaningful progress projects.

Thus, we observe a society structured according to grand projects of economic and social progress, supported by individual, rational choice, while individuals unable to easily locate themselves within such projects are left floundering as they search for activities in which some sense of progress may be experienced. Thompson and Holt (2004) note this as potentially a particular problem for men, and an area where the market is increasingly seen as a resource for such individualised (masculine) progress projects.

\section{Locating progress in leisure consumption}

As progress becomes an individual enterprise, we witness a turn towards consumption and leisure activities as its source, and while a full historical review is beyond this article, we provide an overview of this shift. The Enlightenment shaped a society that emphasises a rationalised discourse of progress, identified by a forward-moving trajectory of identifiable improvements in living standards through the accumulation of goods (Desmond, 2003). According to Lee (1993), the era of growth in the United States between the turn of the 20th century and the 1960s resulted from high wages being paid to those undertaking the repetitive, divided labour necessary for efficient manufacturing. Well-paid workers purchased newly affordable mass-produced goods, recognising that better lifestyles could be achieved through the acquisition of commodities that were worked for. Access to consumer goods became established as an attractive purpose for the dull routines of repetitive and alienating work practices. This also resulted in the separation of work and play as more lives became orientated around out-of-home labour, with the home increasingly cordoned off as a leisure sphere separate from work (Connor, 2005). This dichotomy was therefore adopted from economics for ideological purposes (see Graeber, 2011): 
work was a place of productive, yet increasingly alienating labour, while home was the domain of consumption, where progress was increasingly found. Yet, Fordism also represented a period of homogenised products for standardised lifestyles, and as markets became saturated, growth in production could not be sustained. The promise of (economic) progress through consumption was in danger, as what were once signs of progress and status became the norm (cf. Redmond, 2001). Once everyone owned a car, a refrigerator and a television, these items could no longer be seen as obvious signs of achievement, and therefore, markets needed to constantly find new locations for progress.

For Fiske (2000), this trajectory instilled a preference for newness as an economic necessity and consumption as an ideology that encouraged individuals to be 'up to date'. We therefore witnessed a shift in the location of progress from paid work to the purchase of 'useful' commodities, then the 'latest thing', and most recently unique experiences and leisure consumption (Keinan and Kivetz, 2011). The location of progress in consumption and leisure may also be regarded as gendered, as while (professional) men tended to have 'goal-oriented jobs' where progress was more obvious to them, the absence of meaningful work led women in particular to seek this type of leisure consumption as a form of progress, for example, in keeping up to date with the latest clothing and home decor fashions, (Fiske, 2000). However, just as more women are now able to seek progress in professional work, men too now look to leisure consumption for the progress denied elsewhere, as evidenced by the growing markets for men's fashion and beauty (Bakewell et al., 2006; Mintel, 2012, 2013). Holt and Thompson (2004) suggest that for modern men experiential consumption has ecome a prime location for performances of masculinity, and thus, men negotiate in a pleasurable way, a tension between the responsible breadwinner male role (in which work and social relations may make them feel trapped) and the autonomous rebel role. There are a number of ways in which men may deal with the tension between their desire to pursue progress in consumption and their desire to perform rational masculinity. For example, in videogame consumption, men internalise marketing messages from the videogame industry, using them as a basis for how and why they are supposed to play and talk about play (Thornham, 2008). Walkerdine (2007) notes that although in-game capital accumulation might be seen as an 'ideological shadow' of material economic relations, games may also be understood as action hero fantasies for men that present to players the possibility of winning at social and economic relations games are elsewhere denied. Thus, we can observe creative approaches to solving the 'problem' of maintaining masculinity following this shift towards pursuing progress in leisure consumption. However, there is a risk here in too easily seeing videogame practices as just one more male fantasy. For example, we might recognise that just as Thompson and Holt (2004) note that men may also 'soften the rough edges of their phallic pursuits by incorporating feminine motifs' (p. 23), women may also make identity gains in what may be seen as masculine pursuits, including videogames. As gender roles change, what might 'traditionally' be seem as masculine concerns, for example, progress, may be attractive to women too. Ultimately then, while we acknowledge that progress (and technology) may be seen as 'male', we are cautious about presenting this work as an issue of contemporary masculinity only.

Consumer research documents examples of the labour that produces experiences of achievement and progress in consumption. For example, Campbell's (2005) 'craft consumers' primarily use acts of consumption rather than waged labour to 'realise their potential' and 'express their true selves'. The accumulation of consumer goods also provides feelings of achievement and a sense of purpose in life, often more so than the workplace (Belk, 1995). In other cases, progress is sought in a stream of new consumption experiences (Keinan and Kivetz, 2011), and this playful turn in consumer culture produced not only themed shops, malls and restaurants (for example, see Gottdiener, 2000; Sherry et al., 2001) and 'staged' tourist activities (Urry, 2002) but also a rise in technology-based consumption experiences 
such as videogaming which, as we shall illustrate, become a key source of progress for our participants. Again, when paid work denies experiences of progress, individuals seek new ways to experience it outside of waged labour. Thus, although progress remains an important discourse in practice, discursive practice reproduces this in new forms. However, the location of progress in leisure and consumption can erode the pleasure found in these domains. For example, Belk (1995) recognises that what may begin as an exciting quest to collect risks becoming a burdensome task that the collector feels obligated to complete, while Yee (2006) notes that for videogamers, play may even take on the tedium of a 'second job' as continued play starts to feel like work. Where a desire for progress frames leisure activity, we see how play may come to resemble (unpaid) work that erodes the dichotomy of work and play. This may potentially drive an episodic life, since no one location can finalise progress as consumers move from one job, hobby or lover to another (see Bauman, 2003, 2007).

\section{Work, play and technology}

As playful leisure activities become understood as locations of individualised progress, there is, however, a potential clash with established ideas of play as frivolous and childish, and therefore unsuitable for such projects. Play has been rationalised in modern discourse as the opposite of work, with 'play as child progress' reducing play to a developmental role, enabling infants to learn to be 'useful' adults (see Sutton-Smith, 1997). Indeed, a growing body of work on the educational possibilities of videogames maintains this view (for example, see Gee and Shaffer, 2008; Prensky, 2006). An implication is that for a 'fully developed' adult, play should be redundant, and this is demonstrated in Barber's (2007) diagnosis of an infantilised culture where videogames represent a corruption of economic progress. Perceptions of play as childhood practice for 'real life' (Silverstone, 1999; Sutton-Smith, 1997) dismiss adult play as no more than retained childishness, a distraction from both productive work and 'useful' consumption; adults should devote their time and energy to the real purpose of life through social and economic achievements. In this vein, excessive videogame play has been considered as eroding more meaningful elements of people's lives, as in narratives of addiction and 'problem' videogamers. Here, videogames are described as intentionally addictive, encouraging gambling-like behaviours (Griffiths and Wood, 2000; Loftus and Loftus, 1983), with multiple in-game tasks running simultaneously and 'experience bars' tracking multiple means of progress, leading to extended play (King and Delfabbro, 2009). Adult videogaming may therefore be perceived as potentially destructive, in extreme cases resulting in lost jobs and broken marriages (see Chappell et al., 2006).

The dominant discourses of adult play as trivial and childish, or worse, damaging, may explain the modern use of euphemisms, such as hobbies, pastimes and recreation, and may contribute to both nonvideogamers' reluctance to accept videogaming as a 'normal' adult activity (Newman, 2004) and adult videogamers' tendency to 'rationalise' their videogaming activity in terms of factors other than simply the pleasures of play (Thornham, 2008). For example, Thornham (2008) finds that adult males describe their videogaming in terms of either the utility and functionality of gaming technologies, or with reference to their role as a social lubricant. Thus, we see how adults must discursively overcome tensions between the pleasures of play and what they understand as normal adult behaviours, a contradiction that must be resolved where adult play is positioned as detrimental to progress but is simultaneously becoming a key location for its realisation. A result is a negotiation of the roles of both work and play as locations for progress brought about by the change in both labour and leisure practices described above. 
Csikszentmihalyi (1975) has argued that work time and leisure time are merely culturally defined and that we should therefore not consider play as the opposite of work, but rather might recognise that play as 'flow' is the opposite of boredom and anxiety. Indeed, the taken-for-granted separation of work and play is eroded by recognition of the labour involved in leisure pursuits, alongside management studies' movement away from the idea of 'work as good' and 'play as bad' (Kavanagh, 2011). Hence, companies are increasingly introducing playful activities to overcome work practices that may be experienced as tedious or stressful (for example, see Butler et al., 2011). The conflation of work and leisure may therefore be connected to a more critical line of analysis. Goggin (2011), for example, argues a link to post-Fordist moves towards immaterial labour whereby manual labour is not only replaced by emotional, creative and communicative work, but much of this immaterial labour is undertaken willingly by consumers for free and valorised by companies (see Lazzarato, 1996; Terranova, 2000, 2013). Leisure consumption now often involves working for capital. For example, Kücklich (2005) documents how videogame modders' unpaid 'playbour' adds value to older videogame products, while it is common for online games such as Minecraft to benefit from unpaid gamers who, privileged with the opportunity to play the game prior to its mainstream release, happily work to beta test the game for free. Play therefore re-emerges as useful for capitalism, potentially resulting in more productive 'workers' both paid and unpaid, during work and in leisure. Thus, play is no longer the opposite of progress through productivity, but central to its continuation.

Finally, these trends are to a large degree connected with technology. Technology is the product of the immaterial labour that rescues post-Fordist economies through both flexible working and the valorisation of consumer leisure work. Technology has therefore become central to discourses of progress (Slack and Wise, 2006). One clear, modernist narrative is that it is technology that moves society towards perfection, overcoming any problems along the way, what Kozinets (2008) refers to as a Techtopian ideology. Technology promised a way out of the fixed structures of Fordism with software that is used up in its consumption as a new ideal commodity form (see Kline et al., 2003). Yet, at an individual sense-making level, there is a tension between technology as both liberating and alienating, summed up by Kozinets (2008) as an individualistic 'Techspressive' ideology, where technology is seen to produce pleasure, verses a 'Work Machine' discourse of technology improving productivity, but potentially alienating the worker. Technology may be seen as both a source of alienation and labour exploitation (in its paid work form) and as a way to liberate individuals from this (in its leisure work form).

In summary, individuals retain a desire for achievement and progress that is now separated from the obvious location of waged labour, but remains linked to capitalism even in leisure, where it must overcome the recognition of play as potentially frivolous or childish. Technology presents itself simultaneously as both Work Machine alienation and an always-possible solution.

\section{Videogames and experiences of progress}

In this research, we are concerned with the ways in which adults make sense of videogaming. While previous research has considered the topic (e.g. Thornham, 2008, 2009, 2011) our focus is individualised videogame consumption and its relationship to progress. Between June and October 2006, the lead researcher spent a total of 50 hours talking with 25 adult videogame players ( 6 of whom were women) aged between 18 and 57, in the South of England. Participants ranged from highly skilled gamers with modding capabilities, to more casual players, although all described themselves as having 
considerable gaming experience across a range of platforms (including consoles, personal computer (PC) and handheld) and considered it one of their main leisure activities.

The interviews were phenomenological, in line with similar approaches in consumer research (Hirschman and Thompson, 1997; Thompson, 1996, 1997; Thompson et al., 1989), considering participants' lived experiences of videogame consumption (engagement with videogames and related hardware) within the context of their broader lifeworlds. As Holstein and Gubrium (1998) suggest, we make distinctions between discursive practice (the lived experience) and discourse in practice (the 'traditions' with which people think), thereby highlighting that social discourse is both a resource for and a result of everyday practice.

In discussing their videogame consumption, our participants expressed processes of meaning-making, and this is our interest. However, our approach (often several extended one-to-one interviews) captures more than just what it is perceived as acceptable to say publically about videogaming and includes more private sensemaking. Participants often qualified their stories with 'I know this will sound silly' or 'I don't usually talk to people about this', illustrating both a need to reconcile playing videogames with 'normal' adult behaviour and an awareness of what can be said about them publicly. In these conversations, frequent reference was made to both having 'done something worthwhile' or 'achieved something' with videogames, and the lack of such experiences in descriptions of broader lifeworlds including relationships and especially work. Many of our participants worked in jobs typical of immaterial labour (design, programming, marketing). Most (and all quoted here) were also men, and while our reviewers rightly point out that such progress, and technology in general, may be gendered as masculine, we are cautious of making too many gender distinctions. For example, female participants also provided narratives consistent with progress described here, and more importantly, the male participants provided stories of videogame play involving the more feminine characteristics of social interaction, caring and an absence of competition (see Molesworth et al., 2011), and accounts of the aesthetic beauty to be found in games (see Molesworth, 2009) that are not dealt with here. Videogames may therefore allow for a wide range of gender performances. Nevertheless, we note that the sensemaking described may be largely masculine.

We identify three overlapping sets of practices present in participants' stories that deal with individualised progress projects, and we present these according to their temporal scope (from a life of playing, to achieving something in just a few minutes). First, our participants interpreted consoles and games as constantly 'getting better', and therefore as evidence of technological progress throughout their own lives. For some, this was elaborated by engagement with retro games and consoles, while others eagerly awaited new consoles that would enable the best possible gaming experience. In the second theme, players noted that videogames presented them with specific episodes of progress through the accumulation of 'more' alongside the ability to 'make something'. Finally, videogame play was used to either 'balance out' negative experiences or avoid the angst of wasting time, and these more negative frames illustrate individuals' ongoing struggle to experience progress and their desire to ensure its persistent presence, including through 'play work'.

\section{Videogame commodities as evidence of progress}

Both male and female participants enjoyed making comparisons with older, 'inferior' gaming technology. Many listed each console they had owned, explaining improvements presented by each new generation of hardware (processor, memory, resolution and so on.). 
Luke, a 29-year-old web developer, lives in a modern apartment and places great emphasis on the technology that he owns (especially his car, audiovisual (AV) and computer equipment). He is able to provide a history of the consoles he has owned, from early Nintendo systems and his first PlayStation to a GameCube, followed by his current Xbox. He recalls GameCube games as being the 'best he has played', but explains that he will not return to an inferior console, despite being bored with his current Xbox games. Although he acknowledges that there are many existing games that he is yet to play, he prefers to anticipate something new:

I was going to get a PS3, but they've pushed the date back now, until March or something [. . .]. So I don't know, I'm a bit disheartened 'cause there aren't any new Xbox games, well there are, but they're all ported from 360 from what I can see. I don't know whether to go and get a 360, or be patient ... Well, I should look at the Xbox games I haven't played, but they're old now, and I'm kind of thinking this is not the optimum experience I'm getting now, I'm getting the leftovers. . . like I said before, for me it's about keeping on top of it, getting the latest thing and seeing what the technology can do. [. . .], so I don't think there is anything that will blow me away at the moment. Until I get a PS3 or something.

Luke's anticipation makes him restless and discontent with both his current and earlier technology since they are not the 'latest thing', and engagement with them would therefore feel like a backward step. However, the promise of a new console and games enables Luke to look to the future, believing there is something better on the horizon. Here, we see the desire for new and better videogaming technology - for progress - take precedence over the pleasure of play itself.

Malcolm provides another account. He lives with his wife and teenage children in rural England. A large TV, AV equipment, Xbox 360, Sky+ box and DVD recorder dominate their living room. He also owns an expensive PC, Nintendo DS and a personal digital assistant (PDA). He explains that he purchased the Xbox 360 because he was interested in its 'extended functionality', including use as a media player, although in reality it was not used to play music. It is also networked, yet Malcolm was yet to try online play. Similar to Thornham's (2009) participants, Malcolm often rationalised the technologies themselves in his accounts of videogaming, claiming to be interested in what technology is capable of, and anticipated new developments through engagement with online forums and magazines. Alongside his current technology, Malcolm had an extensive collection of old consoles and software, yet he found himself quickly bored by each new game. For Malcolm, videogame consumption as a hobby was more about collecting and comparing technology than about playing. He discussed his collection at length, carefully noting the condition and value of key items and placing them in their historical context. Later technologies were explained in terms of improvement over earlier products, and it quickly became clear that this collection was ongoing:

A lot of them are in the shed, some are in the loft, and they are kind of spread out ... Spectrums, we must have nine or ten Spectrums, 2 or 3 SNESs, several Master Systems, a couple of Ataris, an Amiga, the Xbox is out there, 5 PlayStations in all the various incarnations.[...] The Spectrums are boxed, in the original black box and with the Horizons tape and that, yeah, I keep those nice, but the other consoles we play around with[. . .]. It's got to be, literally over the years I must have spent thousands on them.

Other players accumulated collections of several hundred games (some of which had never been played) and many consoles (again, with older ones unused for play), and while some claimed that they simply had not got round to selling older games, for others collecting was more important than playing. Rapid changes in the constantly evolving videogame market therefore provide a suitable context for developing a collection that is explained as a never-ending project of achieving something 'complete' and 'special', and simultaneously becomes a record of technological progress. For some, this became a 
conscious process of acquiring 'sacred' items (see Belk, 1995) from videogaming history, but for others, collections were based upon the retention of each generation of hardware and software they had played, and here, collections came to represent individualised progress linked to biographical memories of playing each console. Some collectors further rationalised their hobby by noting an investment potential, taking pleasure in monitoring the increasing worth of their collections on websites such as eBay. Thus, alongside the technological and personal progress they represent, such collections can come to be perceived as a form of economic progress.

In summary, collections of videogames and related hardware came to represent tangible technological progress, 'packages of memories' (Belk, 1995: 92), which together demonstrate a steady series of improvements. Regardless of the pleasures of play itself, by being able to observe technological improvements or by aiming for some 'ideal' and appreciating collection, videogamers are able to manage a sense in which life is experienced as better than before and anticipated as potentially better in the future. While the advancing technology is provided by the videogame market, it is through individualised engagement with videogaming commodities, via collection and reflection and/or anticipation, that consumers are able to experience these advances as progress.

\section{Accumulation, creation and instant gratification}

Participants noted that a sense of accomplishment is something that differentiates videogames from other media consumption or even from other aspects of their daily lives. Episodes of videogaming enabled gamers to experience controlled periods of achievement and progress, demonstrated by an increasing score or an evolving creation. Alex, a 40-year-old experienced gamer and a qualified optician, currently stays at home to look after two school-aged children. This arrangement leaves him with plenty of free time for videogames, and after reviewing his favourite games, he attempted a considered explanation of how they present a pleasurable experience of progress:

I mean they're all about amassing things aren't they? How many headshots you've done, how many tanks you've built, how many countries you've invaded, you know? It's like seeing the naughts in your bank account, there is pleasure in seeing them tick over, or your milometer tick over. In the same way that there is pleasure in going from 9999 experience points to, you know the next level, so games like those they give you - the joy is in saying right, this is what I've amalgamated within the game.

Alex noted that through a process of understanding how to progress through the game, a player gains a sense of both control and recognition of their achievements that are immediately visible. We see how videogames may produce clearly defined episodes of achievement that consequently allow for performances of progress. Their attraction may be attributed at least in part to the speed and ease with which achievement can be realised. Luke discussed the 'instant gratification' provided by videogames, for example:

To some extent if you want to be at the top of the NBA or whatever, you can do it in a game, probably in a weekend, whereas in life all you are going to hit is rejection and well you might succeed, but the chances are small. So in the game you can achieve it, you know it's achievable; it's not just a pipe dream, sort of thing.

This process seems consistent with the criticism that work is experienced as unrewarding for many and that leisure consumption has become a space where we should experience pleasure, particularly in the accumulation of 'more' (Bauman, 2001; Schor, 1991). Other players also articulated a type of play that reflected a desire to achieve a skill that might be otherwise beyond them, or at least not possible in the 
time available. Carl is a married, 41-year-old learning technologist who finds his job boring and repetitive, offering little scope for creativity. He explains at length his desire to create things in games:

\begin{abstract}
In the world we live in often there is very little opportunity to create. [...] My wife is actually quite a good artist, [. . . ] and when we got married she introduced me to that, but I am abysmal [laughs], you would not recognise what I paint, even as abstract art. [. . .] But within a game I can actually create something and I can do it in the comfort of my own home, when I want, I can save it and come back to it. All the artistic stuff in the way it looks is actually done for me so it's Lego [. . . I mean it will always look the same, the same boxy squares. Now, you take Command and Conquer, or Generals to a certain extent, I'm just starting to play that, or Sim City, it will always look the same, but what you've got is the ability to vary what you have created [. . .]. I am actually taking nothing and creating something that if I play with it will actually last.
\end{abstract}

Carl articulates a sense of agency, explaining in detail the elaborate worlds he has built and managed, recognising that he has created 'something worthwhile'. Grant, a 26-year-old single computer technician who works in a high street computer retailer, also discussed the pleasure of making things within videogames. In contrast to his dull and frustrating job, where he endlessly deals with similar computer problems for frustrated and unappreciative customers, Grant described the pleasure of modding and creating new and better games through a series of small improvements:

I like Stargate ... and there's a group of people at the moment who are very skilled in 3D objects, recreating all the ships, doing all the textures and I'm just helping at the moment. I'm getting all the sounds, getting all the weapons right so that we can then release them to the world to play for free. .. I've been trying to change the look of the game, the graphics, the menu system, the weapons for all the ships. At the moment I'm learning how to put another race into a game [...]. The appeal is probably more building the stuff than actually having the battle.

These last two examples demonstrate the potential for 'craft consumption' (Campbell, 2005) in videogame use, and perhaps a more positive reading of play than the performance of material accumulation or instant gratification. Yet, even in these examples, we see that players clearly acknowledge experiences of progress through videogame consumption that contrast with a lack of achievement elsewhere in life. Similarly, two of the female participants reported building elaborate 'ideal' online worlds (one in The Sims; the other in Animal Crossing) that they directly contrasted with their inability to do such things outside of the game. We see compensations then, and a desire to experience progress not in life as a whole, or through paid work, but in transient episodes of play.

\title{
Avoiding stagnation through play
}

The desire for compensation for failure to achieve progress in other domains may be more pressing for some, such that it is perhaps balance, rather than progress, that is sought. Here, videogaming behaviour is reactive to negative feelings. We may see a type of cathartic play, expressed as 'needing to play' to 'get something out of your system'. Recognition of occasional stresses of work and family life that cannot be immediately dealt with produce attempts to displace negative feelings through play. Stephen, an affluent, married production manager in his late 30s, provides an account of this:

Sarah will be getting home from work and having a shower or whatever and she will hear me swearing and she can never understand why I'm playing it if it's creating that much anger, you know. You are supposed to be playing it to enjoy it, and I don't know ... I think it's because quite often, you know, I'll have a bad day at work or something and when you do well in [the game] you do feel very good about yourself.

Stephen goes on to note that it is important to choose the right game for this task. Occasionally, games are too hard and simply intensify feelings of frustration, while games that are too easy fail to provide the desired feelings of achievement. Furthermore, games may become too easy with repeated play and 
may need to be replaced with new ones that present fresh challenges, enabling the gamer to sustain feelings of achievement.

For others, games were seen as a solution to more enduring problems, requiring even more careful management. Stuart, a 57-year-old academic, provided a detailed account of the way in which games, in this case Morrowind, may compensate for ongoing and complex problems at work:

.. every time I had trouble with my boss; in the evening I would just go knock shit out of somebody in the game [laughs] ... It is actually cathartic in the sense that you realise, obviously you are not schizophrenic, so you realise that it's a game, it's a system, it's a world in which you have control, rather than, well the thing that stresses most people is not how difficult or how hard their work is, it's how little control they have in their life ... So it's the illusion that you have control over a small world. It's nothing to do with megalomania, it's to do with achieving something and being recognised for what you have achieved.

In a later interview, Stuart further discussed his negative feelings about his job and the role of games in 'compensating' for this:

Well in a game, if you do well or badly, depends on you. At work there was little I could do to change things [...]. I think the control has more to do with not so much following the quest, but achieving objectives, I'm an objective orientated person. I've always believed in objectives ... And you know you look at what you've got to do, figure out a way of doing it and if you don't achieve it you can reload the game and try again, you can't do that in life [laughs]. So it's more to do with setting yourself objectives, or having someone set an objective for you, and managing to achieve those objectives.

Players may find that when they are not in control of life (in this case paid work), the promise of riskfree progress in videogames can help them cope. In taking responsibility for his own progress, Stuart minimised the risk of failure by opting for easy, controllable and definite experiences of progress through episodes of videogame play rather than attempting to address his problems at work. Similarly, one of the female participants contrasted her mundane job as a driver, with the achievement of winning a race in Gran Turismo on her return home. When events of the day leave players angry or frustrated they look to the more controllable world of the videogame to relieve stress in a way that often provides the sense of achievement persistently denied in everyday life. In such accounts, the hope of achieving progress seems so lost to the individual that simply balancing out negative experiences becomes their new goal.

Finally, individuals described the pressure to fill spare time with productive activities, and achievement through leisure became almost an obligation. Periods of time with no clear aim provoked a form of 'achievement angst', and videogames provided a solution to the unease of doing nothing. Richard, a 30-year-old marketing executive, explained that he is easily bored and feels the need to use his leisure time productively, to 'achieve' something rather than 'waste time':

There are quite often times in my life, evenings or a weekend where I'm waiting for something to happen, or I'm going to go somewhere, I've got time to fill, so I'll use it as a time filler[. . .]. I've got half an hour, I can turn the Xbox on have a quick nine holes on Tiger Woods, or you know, I can actually be somewhere, you know at the rugby pitch, and forty minutes later I can finish, [. . .] so in small amounts of time, you can achieve something.

Thus, we see the role of videogames not only in instances where individuals are denied progress in other domains of their lives, but also when the absence of immediate goals leads to boredom. At such times, videogames may allow feelings to be managed, and we note the episodic nature of such activity. Here, 
achievement is not some grand plan, but short episodes of progress are used to balance moods and relieve boredom.

\section{Videogames and individualised, episodic progress}

Progress may be understood by individuals as one way of making sense of their lives, and yet a lack of progress, particularly in work which may be dull and frustrating, leads individuals to seek new locations for progress, such as consumption and leisure activities. While consumption has previously been regarded as a primarily feminine activity and more commonly a location for female progress (Walkerdine and Bansel, 2010), we add to a body of literature that documents the ways in which men are increasingly looking to consumption for progress, albeit in a technological form that may be particularly suited to masculine identity, although our female participants may suggest that we should be careful in essentialising gender in this way. Indeed, we may consider that gender itself has become more 'liquid' as consumption becomes a growing domain for masculinity and paid work is feminised. As the Sony PlayStation's original advertisement suggests, players (and perhaps men and women) have accepted that it is through this type of leisure consumption that they may truly 'live'.

In making sense of their videogaming in this way, our participants' accounts suggest a form of individualised, episodic progress that allow them to overcome discourses of play as childish and reconcile videogame play with 'normal' adult behaviour. We further note what this may tell us about how these individuals understand the roles of work and play. Here, we see a tension whereby technology is both a source of alienation and labour exploitation, and as a way to liberate individuals from this. To compensate for a lack of progress in alienated technological work, people (perhaps still especially men) 'work at play' through videogame consumption.

First, videogaming commodities themselves represent technological progress with a series of new and improved consoles offering better sound, improved graphics, new functionality and (more elusively) better game play. Each new technology is understood as better than the last, which eventually results in players losing interest in their current games as 'out dated'. We might see the accounts given above as similar to 'traditional' ways in which material commodities may allow for experiences of progress; videogames as a fashion system and source of collections. For some, this includes engagement with older consoles. While 'retro' games may be taken as a rejection of progress, for the collectors we spoke to they were a way to plot their lives against a series of increasingly advanced consoles, or to gain satisfaction as their collection (and its value) grew. Each new release is a 'moment' where the life of the player may be seen as being made better, and reflecting on collections of now inferior technology reinforces consumers' confidence in future progress. Here, play loses its frivolousness in stories of technological, economic and personal progress.

Second, participants described episodes of progress located in the accumulation, creation and instant gratification experienced as they play their current favourite games. Videogames may be structured so that it is easy for players to see accumulation as achievement. Since this 'more-is-better' type of progress has remained a key driver of consumer culture since Fordism, it is perhaps not surprising that within games we also see consumer-like mechanisms (see Denegri-Knott and Molesworth, 2010) such as the acquisition of bigger homes containing more desirable commodities in The Sims or Animal Crossing or a better car with more modifications in Need for Speed. At other times, the accumulation of 'stuff' remains apparent, but the accumulated goods are magic artefacts within World of Warcraft, or spaceships in Eve Online (all examples provided by our participants). Even where commodities are absent, an ever-increasing score confirms achievement. Alternatively, videogames offer the chance to 
actualise what is otherwise not possible, or practical. They allow for creative achievement, a form of 'craft consumption' for those lacking the time, opportunity and skill necessary for similar creative accomplishments in other aspects of their lives. We see this particularly in 'god games', such as Civilization or Command and Conquer, and also in resource management games such as Theme Park Tycoon (again, all mentioned by participants) that require players to make a structure at least partly from their imagination. However, as Bauman $(2000$, 2001) predicts, both these forms of progress accumulation and creation - not only present a justification of adult play, but also reflect a form of instant gratification that lacks long-term commitment, or integration with gamers' broader lives.

Third, videogames present an immediate means of countering negative experiences of frustration, boredom and angst. Individuals seemingly 'defeated' by their working lives banished feelings that the day has 'not gone well' with a period of intense individual play. Here, games are chosen that may be picked up in an instant. For example, winning a few races on Gran Turismo compensates for time wasted in the daily commute, while success at a few levels of Halo compensates for an unsuccessful meeting, argumentative customers or another row at home (again, examples discussed by participants). Here, it is important that the game offers a challenge but is not so difficult that it produces just another failure, and the result is a process of individually managing daily feelings of achievement. The apparent powerlessness of the individual to have a broader impact on the world, to confront political and social structures that may somehow be responsible for life's failings, to even make paid work acceptable as progress, provokes a retreat to spaces where feelings of controllable progress are easily accessed as episodic play. We also see how consumers' desire for persistent progress may lead to 'achievement angst' where individuals feel they are not getting enough from and are therefore 'wasting' their limited free time. In a curious manifestation of a work ethic that originated from a strong sense of the need for economic progress, having nothing to do is unacceptable. For our participants, the videogame market presents a solution, with progress presenting a way of accounting for videogame consumption, while being reproduced through such activity.

Videogames might be seen as just one of many leisure activities that require the endless purchasing of new equipment in return for the promise of individual progress. However, as we have illustrated they are particularly flexible, accessible and compelling in the way they enable consumers to recognise progress in different ways. Thus, videogames may represent the cutting edge of not just technology, but of individualised market solutions to experiences of dull routines of modern work and domestic life where achievement may be elusive.

The use of games as compensation for an unsatisfactory life is quite different from claims that games may be transformatory, enabling the development of strategies for action in the material world, or what Silverstone (1999) refers to as a 'flight simulator for the everyday'. Instead, episodes of videogame play help individuals to deal with a reality they feel they cannot change. As expressed in the PlayStation advertisement at the beginning of this article, videogames may present individuals with what Castronova (2006) describes as 'a few moments of actual joy', and thus we may see videogames as performing a pacifying role in society. Where technology produces alienated, immaterial labour at work, but with the risk of disillusionment and resistance, it also provides meaningful 'play work'. Unlike the structures of valorisation of consumer labour already identified (for example, see Scholz, 2013), here, the aspects of paid work lost through technology are sold back to consumers who purchase the opportunity for meaningful labour.

For such a system to work, there is necessary resistance to the frivolousness of adult play, and here, discourses of achievement, linked to resignation over work circumstances, allow legitimate claims over 
the value of adult play. What is not resisted is the idea of progress itself. Videogames may not help with this more ambitious reflective task. In re-producing ideas of progress in both their use and accumulation of videogames, our participants perpetuate a lifeworld of alienated, productive, paid work. In allowing experiences of progress, videogames reinforce a need for progress and therefore a need for a complex technological marketplace to cater for that need. Indeed, the enjoyable nature of games as a leisure pursuit can be overshadowed by an obligation to achieve constant progress, and frustration where progress is denied. Here, we note that desire for constant progress erodes even playful activities, transforming them into necessary play work that must follow paid work, a system of technological 'progress' that maintains the unsatisfactory labour conditions that drive players to actualise progress in play. This analysis suggests a specific mechanism produced in current capital relations. Rather than alienated work compensated by 'useful' commodities, contemporary capitalism both suggests and denies progress through paid work, then uses consumers' unsatisfied desire for progress to fuel a market for technological leisure.

\section{Conclusion}

Bauman's $(2000,2001)$ 'bottom up' modernism suggests that individuals can no longer look to society to 'make things right' but are required to take personal responsibility for progress. We see how this leads to an increasing fear of personal failure and a reluctance to choose and commit to progress projects, with consumers increasingly seeking experiences of progress in the instantly gratifying, predictable and relatively risk-free domain of leisure consumption, rather than in paid work. This shift is illustrated by the stories provided by adult videogamers, whereby the absence of progress from work and other aspects of their lives leads them to seek episodes of individualised progress in videogame consumption. Such achievement is not part of some grand life plan, but a combination of ongoing collections that demonstrate progress, episodes of achievement helpfully structured by the latest game releases and the pursuit of fleeting moments of achievement to balance negative emotions and avoid moments of boredom or angst. Progress is used to account for participants' videogaming and consequently ideas of adult play as 'frivolous' are overcome, however consumers' need for progress is also re-produced through those actions. We may recognise that this process serves contemporary capitalist production, as play emerges from its frivolousness as legitimate only in compensating for the lack of progress experienced in working practices that remain alienated through technology-driven productivity, which is subsequently achieved through the consumption of latest technological commodities.

\section{References}

Askegaard S and Linnet J (2011) Towards an epistemology of consumer culture theory: Phenomenology and the context of context. Marketing Theory 11(4): 381-404.

Bakewell C, Mitchell V-W and Rothwell M (2006) UK Generation Y male fashion consciousness. Journal of Fashion Marketing and Management 10(2): 169-180.

Barber B (2007) Consumed: How Markets Corrupt Children, Infantilize Adults, and Swallow Citizens Whole. New York: W.W. Norton \& Company.

Bauman Z (2000) Liquid Modernity. Cambridge: Polity Press.

Bauman Z (2001) The Individualized Society. Cambridge: Polity Press.

Bauman Z (2003) Liquid Love. Cambridge: Polity Press.

Bauman Z (2007) Consuming Life. Cambridge: Polity Press. 
Belk RW (1995) Collecting in a Consumer Society. New York: Routledge.

Butler N, Olaison L, Sliwa M, et al. (2011) Work, play and boredom. Ephemera: Theory and Politics in Organization 11(4): 329-335.

Campbell C (2005) The Craft Consumer: Culture, craft and consumption in a postmodern society. Journal of Consumer Culture 5(1): 23-42.

Castronova E (2006) Synthetic Worlds: The Business and Culture of Online Games. Chicago, IL: University of Chicago Press.

Chappell D, Eatough V, Davies MNO, et al. (2006) Everquest - It's just a computer game right? An interpretative phenomenological analysis of online computing addiction. International Journal of Mental Health and Addiction 4(3): 205-216.

Connor S (2005) Playstations. Or, playing in earnest. Static 1(1): 1-11.

Csikszentmihalyi M (1975) Beyond Boredom and Anxiety: Experiencing Flow in Work and Play. San Francisco, CA: Jossey-Bass.

Denegri-Knott J and Molesworth M (2010) Concepts and practices of digital virtual consumption. Consumption, Markets and Culture 13(2): 109-132.

Desmond J (2003) Consuming Behaviour. Basingstoke: Palgrave Macmillan.

Fiske J (2000) Shopping for pleasure: Malls, power, and resistance. In: Schor J and Holt D (eds) The Consumer Society Reader. New York: The New Press, pp. 306-328.

Gabriel Y and Lang T (1995) The Unmanageable Consumer Contemporary Consumption and Its fragmentation. London: Sage.

Gee JP and Shaffer DW (2008) How Computer Games Help Children Learn. New York: Palgrave Macmillan.

Goggin J (2011) Playbour, farming and labour. Ephemera: Theory and Politics in Organization 11(4): $357-368$.

Gottdiener M (ed.) (2000) New Forms of Consumption: Consumers, Culture and Commodification. Lanham, MD: Rowman \& Littlefield.

Graeber D (2011) Consumption. Current Anthropology 52(4): 489-511.

Griffiths MD and Wood RTA (2000) Risk factors in adolescence: The case of gambling, videogame playing, and the Internet. Journal of Gambling Studies 16: 199-225.

Hirschman EC and Thompson CJ (1997) Why media matter: Toward a richer understanding of consumers' relationships with advertising and mass media. Journal of Advertising 26(1): 38 43.

Holstein JA and Gubrium JF (1998) Phenomenology, ethnomethodology, and interpretive practice. In: Denzin NK and Lincoln YS (eds) Strategies of Qualitative Inquiry. Thousand Oaks, CA: Sage, pp. 262-272.

Holstein JA and Gubrium JF (2005) Interpretive practice and social action. In: Denzin NK and Lincoln YS (eds) The SAGE Handbook of Qualitative Research, 3rd edn. Thousand Oaks, CA: Sage, pp. 483-505. 
Holt DB and Thompson CJ (2004) Man-of-action heroes: The pursuit of heroic masculinity in everyday consumption. Journal of Consumer Research 31: 425-440.

Kavanagh D (2011) Work and play in management studies: A Kleinian analysis. Ephemera: Theory and Politics in Organization 11(4): 336-356.

Keinan A and Kivetz R (2011) Productivity orientation and the consumption of collectable experiences. Journal of Consumer Research 37(6): 935-950.

King DL and Delfabbro PH (2009) Understanding and assisting excessive players of video games: A community psychology perspective. The Australian Community Psychologist 21: 62-74.

Kline S, Dyer-Witheford N and De Peuter G (2003) Digital Play: The Interaction of Technology, Culture, and Marketing. Montreal, QC, Canada: McGill-Queen's University Press.

Kozinets RV (2008) Technology/ideology: How ideological fields influence consumers' technology narratives. Journal of Consumer Research 34(6): 865-881.

Kücklich J Precarious playbour: Modders and the digital games industry. Fibreculture [Online]. Available: http://five.fibreculturejournal.org/fcj-025-precarious-playbourmodders-and-thedigital-games-industry/

Lazzarato M (1996) Immaterial Labor (trans. P Colilli and E Emery). In: Hardt M and Virno P (eds) Radical Thought in Italy: A Potential Politics. Minneapolis, MN: University of Minnesota Press, pp. 133-147.

Lee MJ (1993) Consumer Culture Reborn: The Cultural Politics of Consumption. London: Routledge.

Loftus GR and Loftus EF (1983) Mind at Play: The Psychology of Video Games. New York: Basic Books.

Mintel (2011) Video games - UK - November 2011. Available at: http://academic.mintel.com/display/545493/?highlight1/4true (accessed 10 September 2012).

Mintel (2012) Men's toiletries - UK - October 2012. Available at: http://academic.mintel.com/display/640806/?highlight1/4true\#hit1 (accessed 28 March 2013).

Mintel (2013) Menswear - UK - March 2013. Available at: http://academic.mintel.com/ display/638035/?highlight1/4true\# (accessed 28 March 2013).

Molesworth M (2009) Adults' consumption of videogames as imaginative escape from routine. Advances in Consumer Research 36: 378-383.

Molesworth M, Jenkins R and Eccles S (2011) Love and videogames: Negotiating relationships with cultural ideals and consumer practices. Research in Consumer Behaviour 13: 145-162.

Newman J (2004) Videogames. London: Routledge.

Prensky M (2006) Don’t Bother Me Mom - I'm Learning! Saint Paul, MN: Paragon House.

Redmond WH (2001) Exploring the limits to material desire: The influence of preferences vs. plans on consumption spending. Journal of Economic Issues 35(3): 575-589.

Rose N (1999) The Powers of Freedom: Reframing Political. Cambridge: Cambridge University Press. 
Scholz T (2013) Digital Labor: The Internet as Playground and Factory. New York: Routledge.

Schor J (1991) The Overworked American: The Unexpected Decline Of Leisure. Jackson, TN: Basic Books.

Sherry JF Jr, Kozinets RV, Storm D, et al. (2001) Being in the zone: Staging retail theater at ESPN Zone Chicago. Journal of Contemporary Ethnography 30(4): 465-510.

Silverstone R (1999) Why Study the Media? London: Sage.

Slack DS and Wise JM (2006) Cultural studies and communication technology. In: Lievrouw LA and Livingstone S (eds) The Handbook of New Media. London: Sage, pp. 141-162.

Sutton-Smith B (1997) The Ambiguity of Play. Cambridge MA; Cambridge: Harvard University Press.

Terranova T (2000) Free labor: Producing culture for the digital economy. Social Text 18(2): 33-58.

Terranova T (2013) Free labor. In: Scholz T (ed.) Digital Labor: The Internet as Playground and Factory. New York: Routledge, pp. 33-57.

Thompson CJ (1996) Caring consumers: Gendered consumption meanings and the juggling lifestyle. Journal of Consumer Research 22: 388-407.

Thompson CJ (1997) Interpreting consumers: A hermeneutical framework for deriving marketing insights from the texts of consumers' consumption stories. Journal of Marketing Research 34(4): 438-455.

Thompson CJ and Holt DB (2004) How do men grab the phallus? Gender tourism in everyday consumption. Journal of Consumer Culture 4(3): 313-338.

Thompson CJ, Locander WB and Pollio HR (1989) Putting consumer experiences back into consumer research: The philosophy and method of existential-phenomenology. Journal of Consumer Research 16: 133-146.

Thornham H (2008) 'It's A Boy Thing': Gaming, gender and geeks. Feminist Media Studies 8(2): $127-142$

Thornham H (2009) Claiming a stake in the videogame: What grown-ups say to rationalize and normalize gaming. Convergence: The International Journal of Research into New Media Technologies 15(2): 141-159.

Thornham H (2011) Ethnographies of the Videogame: Gender, Narrative and Praxis. Surrey: Ashgate Press.

Urry J (2002) The Tourist Gaze, 2nd edn. London: Sage.

Walkerdine V (2007) Children, Gender, Video Games: Towards a Relational Approach to Multimedia. New York: Palgrave Macmillan.

Walkerdine V and Bansel P (2010) Neoliberalism, work and subjectivity: Towards a more complex account. In: Wetherell M and Mohanty CT (eds) The SAGE Handbook of Identities. London: Sage, pp. 492-507.

Yee N (2006) The labor of fun: How video games blur the boundaries of work and play.Games and Culture 1(1): 68-71. 